were in top scientific institutions: extreme dedication and long working hours, with no supporting hierarchies - what Brady calls a "rat lab". Fellow scientists became her family substitutes and friends, and there she met her future husband, John Sedat.

Blackburn's DNA-sequencing skills were for her the key to discovery, and she took them to Joe Gall's lab in Yale after a short break to climb to Mount Everest's base camp with Sedat. In Gall's lab were some of the future principals of the telomere field - Ginger Zakian, Mary-Lou Pardue and, later, Tom Cech. It was there that Blackburn discovered in 1976 that Tetrahy- mena chromosomes end in a series of repeated runs of cytosine bases that varied in length.

Although this was the first molecular insight into the structure of chromosome ends, it was not seen as important by the community, which is surprising in view of its implications for chromosome replication and transmission of genetic information. Blackburn blames the perception of Tetrahymena as a "freak organism". But it also fell outside what was then mainstream molecular biology. The story repeated itself when she, together with Carol Greider, discovered telomerase in 1985. By then it was clear that telomere replication was a fundamentally important process, but telomerase continued to receive scant attention until 1994-95, when it was shown to be aberrantly activated in most human cancers.

The biography succeeds in capturing Blackburn's vision, which has encouraged her to pursue unbeaten tracks to make discoveries that today hold therapeutic promise for both cancer and ageing.

Maria A. Blasco is head of the Telomeres and Telomerase Group in the Molecular Oncology Program at the Spanish National Cancer Centre (CNIO), Melchor Fernández Almagro 3, 28029 Madrid, Spain.

\title{
Is technology unnatural?
}

\section{The Artificial and the Natural: An Evolving Polarity edited by Bernadette Bensaude-Vincent and William R. Newman \\ MIT Press: 2007. 331pp. $\$ 40$}

\section{Philip Ball}

The topic of this book - how boundaries are drawn between the natural and the synthetichas received too little serious attention, both in science and in society. Chemists are justifiably touchy about descriptions of commercial products as 'chemical-free', but the usual response, which is to lament media or public ignorance, fails to recognize the complex history and sociology that lies behind preconceptions about chemical artefacts. The issue is much broader, however, touching on areas ranging from stemcell therapy and assisted conception to biomimetic engineering, synthetic biology, machine intelligence and ecosystem management.

And it is not an issue for the sciences alone. Arguably, the distinction between nature and artifice is equally fraught in what we now call the fine arts - where again it tends to be sidestepped. Some modern artists address the matter head on with their interventions in nature - for example, the artificial rainbows of Andy Goldsworthy - but much popular art criticism now imposes a contemporary view, even on the old masters. Through this lens, Renaissance writer Giorgio Vasari's astonishment that Leonardo's painted dewdrops "looked more convincing than the real thing" seems a little childish, as though he has missed the point of art. No one today believes that the artist's job is to mimic nature as accurately as possible. Perhaps with good reason, but it is left to art historians to point out that there is nothing absolute about this view.

At the heart of the matter is the fact that 'art' has not always meant what it does today. Until the late Enlightenment, it simply referred to anything human-made, whether a sculpture or an engine. The panoply of mutated creatures described in Francis Bacon's The New Atlantis (1627) were the products of 'art', and so were the metals generated in the alchemist's laboratory. The equivalent word in ancient Greece was techne, the root of 'technology' of course, but in itself a term that embraced subtle shades of meaning, examined here in ancient medicine by Heinrich von Staden and in mechanics by Francis Wolff.

The critical issue was how this 'art' was related to 'nature', roughly identified with what Aristotle called physis. Can art produce things

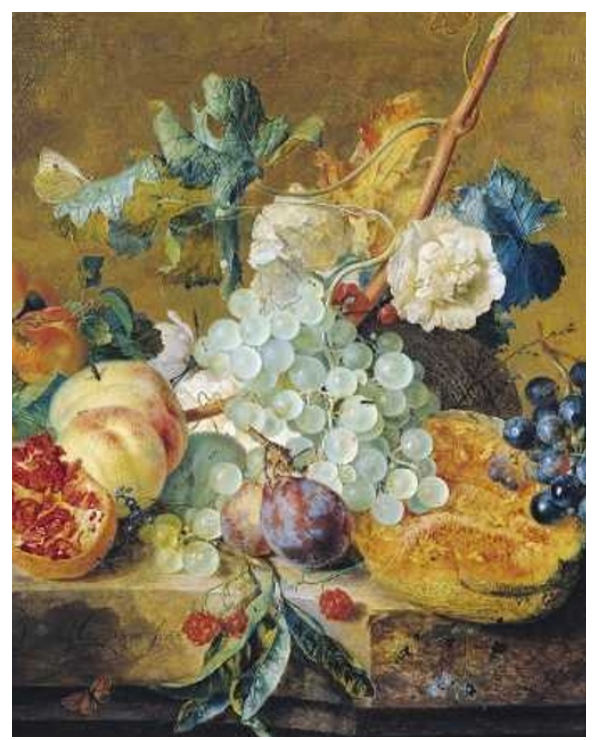

Oil painting by Jan van Huysum (1682-1749): does art imitate nature, or improve on it?

identical to those in nature, or only superficial imitations of them? (The latter belief left Plato rather dismissive of the visual arts.) Does art operate using the same principles as nature, or does it violate them? Alchemy was commonly deemed to work simply by speeding up natural processes: metals ripened into gold sooner in the crucible than they did in the ground, and (al)chemical medicines accelerated natural healing. And although some considered 'artificial' things to be inferior to their 'natural' equivalents, it was also widely held that art could exceed nature, bringing objects to a greater state of perfection, as Roger Bacon believed of alchemical gold.

The emphasis in The Artificial and the Natural is historical, ranging from Hippocrates to nylon. These motley essays are full of wonders and insights, but are ultimately frustrating in their microcosmic way. There is no real synthesis on offer, no vision of how attitudes have evolved and fragmented. There are too many conspicuous absences (Leonardo da Vinci for one) for the book to represent an overview.

It would have been nice to see some analysis of changing ideas about experimentation, the adoption of which was surely hindered by Aristotle's doubts that 'art' (and thus laboratory manipulation) was capable of illuminating nature. Prejudices about experiments often went further: even in the Renaissance, one was free to disregard their results if they conflicted with a priori 'truths' gleaned from nature, rather as Pythagoras advocated studying music by "setting aside the judgement of the ears". And it would have been fascinating to see how these issues were discussed in other cultures, particularly in technologically precocious China.

But most important, the discussion sorely lacks a contemporary perspective, except for Bernadette Bensaude-Vincent's chapter on plastics and biomimetics. This debate is no historical curiosity, but urgently needs airing today. Legislation on trans-species embryology, reproductive technology, genome engineering and environmental protection is being drawn up, based on what sometimes seems to be little more than a handful of received wisdoms (some of them scriptural) moderated by conventional risk analysis. There is, with the possible exception of discussions on biodiversity, almost no conceptual framework to act as a support and guide.

All too often, what is considered 'natural' assumes an absurdly idealized view of nature that owes more to the delusions of Rousseau's romanticism than to any historically informed perspective. By revealing how sophisticated, and yet how transitory, the distinctions have been in the past, this book is an appealingly erudite invitation to begin the conversation. Philip Ball is a consultant editor for Nature. His most recent book is The Devil's Doctor (Heinemann/FSG, 2006). 